INVESTIGACIONES

de HISTORIA ECONÓMICA

2008, otoño, número 12. Pp. 111 a 140

\title{
Las agencias de informes crediticios en la Argentina: una aproximación al funcionamiento de los mecanismos informativos en el mercado crediticio, 1892-c.1935
}

\author{
Credit-reporting agencies in Argentina: A historical exploration \\ of information sharing mechanisms in credit markets, 1892-c.1935
}

\author{
ANDREA LLUCH \\ Harvard Business School y CONICET
}

RESUMEN
¿Cómo mitigar los efectos de la información
asimétrica en la extensión del crédito? Los
principales objetivos de este trabajo son enfatizar la severidad del problema informativo dentro de la extensión del crédito comercial en la Argentina de principios del siglo XX y resumir los rasgos básicos del surgimiento de empresas destinadas específicamente a proveer

informes comerciales. Para ello, el artículo centra su atención en la comunidad mercantil e intenta mostrar la complementariedad de distintas vías —internas y externas - para acceder a la información sobre los posibles prestatarios por parte de los proveedores,

facilitando con ello el acceso al crédito comercial. La organización de la primera agencia de informes comerciales en la Argentina es el punto de partida de este artículo para culminar en los años treinta, cuando confluyeron una serie de procesos que renovaron los desafíos para la consolidación y regulación de este sector.

PALABRAS CLAVE: Informes comerciales, Agencias, Crédito, Información, Argentina

Códigos JEL: N26, 016, N76, N86
ABSTRACT

During the last decades, economic theory has devoted considerable attention to the role of information asymmetry in credit markets and problems connected with this phenomenon. However, institutional aspects - particularly, how information is gathered and sharedhave not been studied as thoroughly. Only recently has research been conducted on the origins of credit-reporting agencies and on the different responses lenders designed to minimize the impact of information asymmetries. As far as Latin America is concerned, there is no previous historical research available. In that sense, this paper aims to depict some of the mechanisms used within the Argentine business community at the beginning of the twentieth century to generate and disclose information about borrowers, with particular emphasis on Argentina's first credit-reporting agencies.

KEY WORDS: Credit-reporting Agencies, Credit, Information, Argentina

JEL Codes: N26, 016, N76, N86 


\section{Introducción ${ }^{1}$}

L

os avances de la teoría económica y de la información han estimulado, durante los últimos veinte años, una reconfiguración de la teoría de la intermediación financiera. En primer lugar, como señalan Hoff y Stiglitz (1990), los mercados crediticios no deben ser estudiados como mercados competitivos clásicos; $\mathrm{y}$, en segundo lugar, debe reexaminarse la hipótesis de la información perfecta, por la cual se postula que los prestadores tendrían menor conocimiento que los prestatarios sobre las características y resultados de los proyectos de inversión ${ }^{2}$. El rol central de la información asimétrica en el funcionamiento de los mercados crediticios ha recibido, por tanto, una creciente atención desde hace ya décadas en la teoría económi$\mathrm{ca}^{3}$. Y si en la literatura teórica se han analizado extensamente sus consecuencias ${ }^{4}$, se ha prestado menor atención a las respuestas institucionales que los prestamistas han desarrollado para minimizarlas.

Una de las posibles respuestas ha sido la creación de las "agencias de crédito", que recopilan, distribuyen y con frecuencia analizan información sobre el comportamiento de los prestatarios. Con ello pueden contribuir a reducir los problemas de selección adversa y riesgo moral. Estos temas han sido objeto de estudios recientes, destacándose los aportes realizados por Pagano y Jappelli (1993), quienes proporcionan el primer tratamiento riguroso de los mecanismos para compartir información desde la teoría económica. El estudio de estos temas ha cobrado, asimismo, una

[Fecha de recepción del original, enero de 2007. Versión definitiva, febrero de 2008]

1 Agradezco los comentarios y sugerencias realizadas en el Taller de Historia de Empresas organizado por el CEEED-UBA (Buenos Aires, Argentina) en junio del 2005 y coordinado por María Inés Barbero, Rory Miller, Javier Vidal y Marc Vallières. Desde ya, las falencias de este texto son de mi exclusiva responsabilidad. Asimismo, mis agradecimientos a la Comisión Fulbright Argentina, pues gracias a su apoyo fue posible acceder a materiales de gran utilidad para la elaboración de este artículo. También agradezco sus sugerencias a los evaluadores anónimos de Investigaciones de Historia Económica.

2 El papel de la información en la coordinación de las actividades económicas fue enfatizado por Hayek, referencias al particular en el volumen compilado por Casson y Rose (1998). El problema de cómo es adquirida la información y la manera en que circula es un aspecto muy importante. En la economía clásica este tema no es tenido en cuenta (la información es perfecta), mientras que en los últimos años se ha comenzado a señalar que la información no es un bien libre en el mercado, los individuos tiene limitado conocimiento y esto, a su vez, sería una variable dependiente de sus redes de relaciones. Un artículo clásico de la corriente de la economía de la información es el de Stigler (1961).

3 Véanse los ya clásicos trabajos de Stiglitz y Weiss (1981) y Jaffee y Russell (1976), entre otros autores. Otras referencias en Leland y Pyle (1977).

4 En general, los prestamistas sólo poseen información parcial sobre los prestatarios potenciales y sus proyectos de inversión, lo que puede introducir una selección adversa en el mercado de crédito. Una vez que se ha otorgado un préstamo, los prestamistas enfrentan el riesgo moral, es decir, la posibilidad de que los prestatarios traten de evitar amortizar el préstamo o tomen medidas que incrementan el riesgo del proyecto de inversión (Ayala, 1999). 
alta significación analítica al ser considerado un factor clave para facilitar el desarrollo de los mercados financieros y crediticios a nivel mundial ${ }^{5}$.

En este sentido, a pesar de las discusiones teóricas y las recientes investigaciones sobre los registros de crédito actuales, es escasa la atención que ha recibido este tema en sus aspectos institucionales (cómo los actores obtienen y transmiten información). Tampoco se han analizado los orígenes históricos de las agencias crediticias o las distintas respuestas institucionales que los prestamistas desarrollaron para minimizar el impacto de la información asimétrica. De hecho, no existen investigaciones históricas sobre el particular para América Latina. Este trabajo pretende aportar algunas reflexiones preliminares sobre estas cuestiones, que den cuenta, en concreto, de los distintos mecanismos utilizados por la comunidad empresarial argentina para generar y distribuir información crediticia durante las primeras décadas del siglo XX.

El trabajo busca ilustrar cómo los habilitadores del crédito comercial buscaron reducir la incertidumbre y mitigar los efectos de la información asimétrica. Especial atención se presta al sector minorista de la Argentina por tratarse del grupo más numeroso de solicitantes de crédito comercial. La estrategia para abordar estas problemáticas recayó en la combinación de información publicada e inédita. En el primer caso, se apeló a la prensa periódica, a informes contemporáneos y, en especial, a las publicaciones de las propias agencias de informes crediticios. Merece destacarse la riqueza del corpus editado por la firma Veritas, empresa fundada por Antonio Rizzuto en 1919. Complementariamente, fue de enorme utilidad el acceso a archivos de empresas comerciales radicadas en el Territorio Nacional de La Pampa. Ambos registros ilustran la complejidad de estos temas y la continuidad de los canales informales junto a la operación de las nuevas empresas de reportes crediticios.

En cuanto a su estructura, el artículo recorre en primer lugar los diferentes mecanismos utilizados por los habilitadores del crédito comercial para acceder a la información, clasificar a la clientela y operar a crédito con los miles de comerciantes surgidos a la luz de la expansión económica de principios del siglo XX. En la primera parte se detiene en los mecanismos informales e intenta mostrar la utilidad de las redes comerciales para la provisión de referencias crediticias, en especial entre comerciantes del interior rural y sus proveedores de Buenos Aires. La segunda parte del trabajo describe las distintas vías externas de información

5 Algunas de estas investigaciones han sido publicadas en un volumen compilado por Miller (2003), donde se presenta el primer estudio comprensivo sobre los distintos sistemas de información crediticia, públicos y privados, con información sobre 80 países. Esta obra colectiva fue el fruto de una investigación financiada por el Banco Mundial. 
y dedica especial atención a la organización de la primera agencia de informes comerciales de Argentina ${ }^{6}$. Posteriormente, se examinan las características de este sector empresario en el país, centrándose el análisis en el caso de la empresa Veritas. Finalmente, se examinan los desafíos que afrontaron las agencias en los primeros años de existencia. En términos generales, el trabajo intenta reconstruir las diferentes instituciones utilizadas para compartir información y facilitar con ello la extensión del crédito comercial en la Argentina de principios de siglo $\mathrm{XX}$.

\section{Las fuentes de información crediticia}

Ante el riesgo que implicaban las operaciones a crédito, las preguntas lógicas de los habilitadores eran: ¿Conozco objetivamente a mis clientes? ¿Tendrán los antecedentes, trayectoria comercial y solvencia que manifiestan? Ante tales interrogantes, los habilitadores del crédito comercial intentaban cubrirse exigiendo colaterales (pagarés). Pero la complejidad de las transacciones, y el riesgo de incumplimiento, los colocaba en la situación de ejercer una "constante y severa vigilancia a fin de tener siempre al día la situación moral y material de las firmas y la apreciación constante de las alternativas que sufre un cliente", como recomendaba Gastón Lestard en su obra Tecnicismo y practica del descuento y normas científicas y económicas para la distribución de los préstamos, editada en 1929 (Lestard, 1929).

El ritmo expansivo de la economía argentina otorgó una peculiar dinámica al proceso. El incremento del mercado interno fue tan meteórico como el de las exportaciones. Considerado como producto total, el de 1916 era nueve veces mayor que el de 1881. Las cifras del aumento se relacionaban, en parte, con la pequeñez de la economía argentina en 1880, pero también con el considerable aumento de la población

6 Algunas de las sociedades que se dedican en la actualidad a esta actividad (cuyo centro de operaciones habitualmente se encuentra en la ciudad de Buenos Aires) son Organización Veraz S.A. (Equifax), Fidelitas S.A., y Dun E Bradstreet Arg. S.A., entre otras. Además, funcionan dos grandes asociaciones empresariales: la Cámara de Empresas de Información Comercial, que agrupa a catorce empresas del sector, entre ellas las mayores del rubro; y la Federación de Entidades Empresarias de Informes Crediticios de la República Argentina, que agrupa a algunas cámaras de comercio que operan en distintas plazas del interior del país. Muchos de los informes contienen material originado y/o concentrado en bases de datos del Poder Judicial, el Banco Central de la República Argentina (desde 1996, Central de Deudores), el Boletín Oficial, etcétera; y puede accederse a ellos por distintas vías, algo que representa una situación diferencial respecto a la etapa objeto de estudio. 
y del ingreso per capita —respectivamente, un 55 y 45 por 100 entre 1880 y 1914 -. Durante el período se registró, además, una elevada tasa de crecimiento del sector mercantil. Los datos del Censo Nacional de 1895 indican que el 60 por 100 de todos los comercios del país se correspondía con la categoría de almacenes de comestibles y bebidas al por mayor y al por menor. El rubro alimentación representaba el 42 por 100 del total de los comercios, proporción que en 1914 aumentó a casi el 60 por 100. La representatividad del sector minorista, y dentro de ellos de los clásicos "almaceneros" — denominación local para las casas de venta de artículos de consumo-, era indiscutible, tanto en términos urbanos como rurales.

Un ejemplo de la influencia de este sector en la economía de la ciudad de Buenos Aires se refleja en el censo de $1913^{8}$. Los minoristas dedicados a la venta de comestibles y bebidas - frente a otras 165 categorías comerciales- representaban entonces, y en orden de importancia, los primeros por el número de establecimientos $^{9} \mathrm{y}$ capitales, los segundos por el número de personal empleado y los cuartos por el monto de ventas.

Pero estos procesos no sólo afectaron a las áreas urbanas. En las áreas rurales, y al ritmo del vertiginoso poblamiento originado en las "tierras nuevas" por el boom económico de fines del siglo XIX, se produjo el surgimiento de una red de poblados. En ellos, o junto a ellos, se organizaron millares de almacenes y tiendas, representando en estas zonas la manifestación casi dominante del sector comercial. Como puntualizó Cortés Conde (1982), en estos años se originó la difusión urbana más notable en la Argentina desde 1880, aún por encima del enorme crecimiento de la ciudad de Buenos Aires. En dicha instancia fue clave el papel jugado por el ferrocarril, pues al bajar los costos en tiempo y dinero del transporte, tendió a uniformar el comercio y el consumo, acercó a la ciudad y al campo. Los vapores de cabotaje redujeron los fletes, mientras que los ferrocarriles lograron descensos significativos en la carga terrestre y disminuyeron la distancia física entre las distintas provincias (Brown, 2002 [1979], p. 380).

7 Otros indicadores del desenvolvimiento económico argentino entre 1880 y 1914 son, a modo de ejemplo, una tasa anual de crecimiento de la urbanización del 5,4 por 100, de las vías del ferrocarril del 10,6 por 100, de las exportaciones de trigo del 9,9 por 100, del valor total de las exportaciones del 15,2 por 100 y de la producción fabril del 9,3 por 100. Datos extraídos de Brown (2002 [1979]), p. 287. Mayores detalles sobre las características del crecimiento económico argentino durante este período en Díaz (1983).

8 Datos extraídos del censo de 1913 de la Dirección General de Comercio e Industria. El boletín n 20 de dicha dependencia, fechado en 1914, editó los resultados del Censo Comercial e Industrial de la República con los datos de Capital Federal. Dirección General de Comercio e Industria (1914), p. 3.

9 Frente a los 6.038 locales de venta de comestibles y bebidas por menor, continuaban las peluquerías (1.932); las carnicerías (1.563); las tiendas y mercerías (1.530); los hoteles, restaurantes y fondas (1.323); y las confiterías, cafés y billares (1.105). El resto de los comercios no superaba el millar. 
Ello favoreció una enorme concentración de negocios en la ciudad de Buenos Aires, desde donde se expandían las redes comerciales y crediticias, consolidándola como el centro industrial, financiero y comercial del país. La poderosa comunidad radicada en Buenos Aires se mostró decidida a ampliar sus intereses hacia la vasta geografía argentina y demostró una marcada agilidad para responder y potenciar el crecimiento del mercado interno, tal como ha puntualizado Rocchi (2006).

En la estructuración del mercado nacional fue significativo el aporte de las casas comerciales e industrias de Buenos Aires. Éstas, al otorgar plazos más prolongados en sus ventas y con bajos intereses (hasta seis meses sin interés y luego de este lapso con tasas de interés variables), sostuvieron la actividad comercial de los minoristas urbanos y rurales ${ }^{10}$. Al respecto, y como más adelante puntualizaremos, la financiación del crédito productivo y del consumo de la creciente población argentina implicó la estructuración de un sistema en donde los agentes habilitadores debían otorgar créditos con vencimientos amplios, puesto que, en última instancia, gran parte del sistema comercial descansaba en la inyección de liquidez que se producía sólo una o dos veces por año.

En ámbitos rurales estas características se agigantaban. A grandes rasgos, puede establecerse que para las demandas de liquidez en los meses de cosecha los minoristas se apoyaron en bancos y compañías exportadoras de cereales, mientras que, para la ampliación de los circuitos comerciales y financieros, fue fundamental el crédito otorgado por las casas comerciales e industrias de Buenos Aires. El largo plazo en las ventas a crédito se conjugaba con la escasa presentación de garantías. Como indicaba una publicación en 1900: “La causa de las numerosas quiebras proviene de la falta de capital con que trabaja una no despreciable parte de los minoristas. Algunos de ellos hay que con lo estricto solamente para montar armazones y estanterías se han arrojado a establecer pomposas tiendas y negocios (...). En su afán de vender nadie habrá reparado en garantías (...). Hoy más que nunca cuando se acerque un postulante al mayorista este último tiene que inquirir, que informarse aquilatando la capacidad comercial del solicitante"11.

Pero en la medida en que la información no es libre ni gratuita, sino que su recolección y su procesamiento conllevan costos, los habilitadores de crédito comercial, en sus diferentes formatos, desarrollaron una serie de mecanismos para acceder a la información, clasificar a la clientela y operar a crédito con los miles de comerciantes

\footnotetext{
10 Para un análisis del sector de comerciantes importadores radicados en Buenos Aires, véase Fernández (2004).

11 Ecos Comerciales y Judiciales, Revista Semanal, 311, Año VI, 7 de septiembre de 1899. Debe indicarse que no existen estudios específicos sobre el sector minorista de las grandes ciudades argentinas, y en especial de Buenos Aires, para este período.
} 
surgidos a la luz de la expansión económica de principios del siglo XX. Las fuentes de información para los negocios son múltiples y variadas, y si bien la tecnología ha tenido históricamente un alto impacto en su obtención, recolección y procesamiento ${ }^{12}$, se distinguen dos vías principales, las internas y las externas.

\subsection{Vías internas: redes interpersonales}

Las denominadas vías internas, de fisonomía múltiple y cambiante, se distinguen por la recolección e intercambio de información apelando a contactos interpersonales y redes interempresarias ${ }^{13}$. La recolección de información sobre los posibles tomadores de crédito era necesaria, pues al inicio de sus transacciones el grueso de los comerciantes no se conocía personalmente (Olegario, 2006; Sylla, 2002). En tal sentido, información sobre reputación y antecedentes comerciales fluían al interior de la comunidad mercantil, apoyándose, por ejemplo, en cartas de recomendación y en el uso de referencias personales o tarjetas de presentación.

El cambio de escala de negocios y de tecnologías de fines del siglo XIX — con la consecuente reducción en los costos para obtener y en especial difundir datos- no conllevó en forma inmediata la desaparición de los canales informales. Las vías internas de recolección de información sobrevivieron durante esta época, mientras que simultáneamente se extendían los nuevos servicios y mecanismos representados por las oficinas de crédito y las agencias de reportes crediticios.

La supervivencia y la complementación entre ambos canales han podido detectarse mediante el análisis de documentación epistolar de empresas minoristas, en especial de una casa de comercio establecida en el interior de Argentina, específicamente en la actual provincia de La Pampa ${ }^{14}$. Esta empresa, dedicada al comercio minorista de "ramos generales", giraba bajo la razón social de Torroba Hermanos. Esta sociedad operó desde 1897 en una extensa zona desde un "escritorio comercial" en Buenos Aires y sus sucursales en 9 de Julio (Dennehy), Santa Rosa (La Pampa) y Carhué (Provincia de Buenos Aires). La documentación epistolar de esta empresa, representante del modelo predominante de comercios del interior rural de la Argentina, muestra cómo este tipo de comerciantes proveían de información crediticia a numerosas empresas. Los proveedores, bancos e industriales de Buenos Aires no podían apelar a la proximidad física para la clasificación de los potenciales clientes, y por lo tanto utilizaron a terceros.

12 Véase Casson (1997) para vincular la relación información-tecnología con los costes de transacción.

13 Powell (1990) y Brown y Rose (1993).

14 Para el análisis de la operatoria de estos comercios en el interior de la Argentina y los aspectos básicos del funcionamiento del crédito rural y comercial entre 1900 y 1930, véanse Lluch (2004) y (2006). 
La voluminosa correspondencia rescatada, y lo extendido especial y temporalmente de las requisitorias recibidas, permiten establecer la presencia del intercambio de información entre comerciantes. En los miles de folios que componen la correspondencia de esta empresa, se detectan los recurrentes pedidos de información. En sus respuestas los comerciantes solían indicar: "respecto a la firma que nos pregunta"15. Los principales usuarios de estos "servicios" informales fueron las casas mayoristas de Buenos Aires junto a importadores y empresas multinacionales (Agar Cross, International Harvester, West India Oil Co., United States Rubber, entre otras), y exportadoras de cereales e industrias (Bodegas Giol, Terrabusi y otras). El Banco de la Nación y el Banco Español del Río de La Plata también hacían llegar sus cuestionarios y preguntas ordenadas de tal forma que expresaran el "verdadero indicador del concepto que la firma merece al informante". Por último, el profuso conocimiento del área local provocaba que los comerciantes actuaran como informantes para las agencias mercantiles. Torroba, por ejemplo, envió informes a firmas tales como The British Information Bureau, La Opinión Comercial, Agencia Comercial Mayo, R. S. Dun y Cía. (Dun \& Bradstreet Co.) y El Asesor del Comercio.

Al momento de proveer información sobre posibles clientes recurrían, como señalamos, a su cercanía y conocimiento directo; a la par que mencionaban en sus descripciones los comentarios escuchados en sus salones de ventas y pronunciados por terceros. También señalaban el recurso a la observación y pesquisa directa, lo cual a veces implicaba entrevistarse con otro posible informante ("semanalmente hago una visita a este banco o tenemos visto al", ya sea el jefe de policía, juez, o gobernador). En los folios se repetían las siguientes frases "he averiguado por", o "hemos averiguado bien". Si dichas técnicas no bastaban, los comerciantes locales recurrían a métodos indirectos. En estos casos, en sus informes aclaraban que la provisión de datos era producto de "nos dicen..., más que por informes anteriores...; un cliente de nuestra confianza nos da los datos que van al dorso...; y estos días preguntamos entre nuestras relaciones por referencias...; un amigo nuestro nos suministra los siguientes datos". Si estos recursos eran insuficientes, enviaban personal con la misión de obtener los datos solicitados ("el práctico que mande es de confianza") o extendían cartas a colegas solicitando mayores referencias.

15 En la correspondencia comercial de Torroba, entre 1897 y 1933, se refleja claramente el peso que ocupaba la provisión de informes sobre otros comerciantes de la zona (franja este de La Pampa). Una parte de las referencias comerciales, que estimamos son una minoría, se cuelan entre los folios de los libros copiadores. Esta colección comprende 50 libros de 1.000 folios cada uno. En los años veinte organizaron los libros copiadores de referencias comerciales. Lamentablemente, sólo uno de estos libros ha sobrevivido. Se trata de un libro de 467 folios, que cubre los años 1931 a 1935, donde hay más de 600 informes. Esta colección se encuentra depositada en el Archivo Histórico Provincial de La Pampa (AHPLP, en adelante), Santa Rosa, Argentina. 
La evidencia disponible demostraría así la funcionalidad de los mecanismos informales en la provisión de dispositivos para obtener información crediticia. Aquí se detectaría, además, la facilidad de los comerciantes de campaña para convertirse en recolectores y transmisores de información de otras firmas de la zona ante proveedores y bancos que operaban en la ciudad de Buenos Aires. La pervivencia de los mecanismos informales también debe ser analizada en función de un entramado de redes comerciales donde circulaba crédito y productos, además de información. Dicho rasgo ayudaría en parte a explicar la persistencia de la clásica costumbre de recaer en "informantes locales" generando endógenamente información crediticia, mientras de modo simultáneo se desarrollaban otro tipo de mecanismos.

\subsection{Vías externas}

La segunda vía de acceso a la información crediticia, la externa, también combinaría una serie de estrategias. En este nivel tampoco puede desconocerse la combinación de vías informales o de intercambio de información entre empresas, junto con otra serie de recursos de tipo directo, como entrevistas y requisitoria de documentación contable.

En el almacenamiento y difusión de información, un nivel sobre el cual nos interesa llamar la atención es la creciente disponibilidad de guías, anuarios, y revistas comerciales e industriales. Es sorprendente, y refleja el dinamismo del sector comercial de la época, la enorme proliferación de publicaciones para y del mundo de los negocios. Si bien es posible registrar publicaciones especializadas en negocios y mercados desde principios del siglo XIX, a partir de los años ochenta se incrementaron en número y en calidad informativa, surgiendo empresas destinadas a cubrir la demanda de información de un mercado en constante y rápida transformación. Sólo a modo de ejemplo, puede reseñarse que el Boletín número 14 del censo de 1912 estuvo dedicado a la prensa periódica de la ciudad de Buenos Aires. Su ordenamiento, por "carácter y objeto de la publicación", arrojó un total de 795, de las cuales 126 podrían incluirse en la categoría de economía y negocios. Otras 123 publicaciones se registraron como proveedoras de "Servicios e instituciones anexas", de las cuales 47 no entrarían dentro del "mundo de los negocios", pero las demás podrían contener información vinculada a éstos y a la economía.

Pero la mayoría de estas publicaciones periódicas no ofrecían servicios de referenciación crediticia, por la complejidad que ello acarreaba. Lo más cercano, en el sentido de informar sobre los nombres y las empresas operando en el mercado, fueron las Guías Comerciales y Almanaques, pues en ellas se listaban las fir- 
mas en operación y se brindaban datos escuetos sobre responsables y capital societario $^{16}$.

Dentro del sector de materiales editados para afrontar los problemas informativos, la novedad más importante, aunque no parece haber tenido en Argentina la centralidad que ocupó en otros contextos, fueron los "libros de referencias crediticias" $(\text { reference book })^{17}$. Éstos son el ejemplo más acabado de la edición de herramientas tendentes a brindar información inmediata sobre los posibles sujetos de crédito. En el caso argentino, el primer antecedente encontrado es una publicación de 1899 bajo el título de Veritas. Este volumen estaba destinado a los grandes importadores, bancos y comerciantes de Buenos Aires, Rosario y Montevideo. Se trataba de la primera edición de una publicación de origen francés. El prólogo mencionaba:

"modelo de las obras de crédito que se publican desde largos años ha, en la América del Norte, Inglaterra, y Europa y que prestan diariamente inmensos servicios a los bancos, banqueros y comerciantes que obtienen por este medio pronta e inmediata los informes referentes y señas que le son necesarias, facilitando así considerablemente las transacciones financieras y comerciales entre los distintos países"18.

Cada empresa incluida en Veritas había sido clasificada, por lo cual se indicaba que la información allí contenida era "esencialmente confidencial, hecha con la mejor buena fe del editor". Si bien retomaremos luego las dificultades para la confección de los informes crediticios, Veritas destacaba que los criterios para su redacción habían sido: "perspicacia, imparcialidad, autoridad, firmeza, buena fe, buenas fuentes, delicadeza, consejo y opinión de personalidades (para recabar datos y calificar)". Para la caracterización de cada firma, aclaraban, no se habían guiado por ideas preconcebidas ni interés alguno, sino simplemente por el capital y el modo de trabajar de cada empresa. Se trataba de un servicio "sin garantía ni responsabilidad de su parte, según costumbre en tal caso".

La circulación de este tipo de libros, como era usual, se encontraba restringida a los suscriptores. En la introducción se alertaba de la necesidad de guardarlo con "la vigilancia más absoluta y bajo su custodia personal". La novedad de este libro fue la

16 Otra categoría a incluir son los diccionarios biográficos. La importancia de conocer, dentro de una comunidad en permanente cambio, "quién es quién", cobró vigencia a medida que avanzaba el siglo XX. Recién en 1917 pudo presentarse en Argentina la primera edición de Hombres del Día (Hombres del día, 1917), publicación que seguía los lineamientos de las ya tradicionales compilaciones americanas y europeas del Who is who.

17 Un análisis sobre la edición de estos libros para Canadá en Vallieres (2005). Información sobre la experiencia estadounidense en Norris (1978), pp. 141-143.

18 Cada ejemplar contemplaba un recibo de venta y número. El disponible en la Biblioteca Prebish del Banco Central de la República Argentina es el 1.085, perteneciente a la casa Samuel B. Hale y Cía. 
clasificación de las firmas bajo el sistema de key rating, modelo de letras impuesto desde 1857 por la firma norteamericana Bradstreet Co., rápidamente adaptado para "clasificar" a las firmas como sujetos crediticios a nivel internacional.

Este volumen, por tanto, constituyó el primer paso hacia la provisión de un insumo básico para el comercio europeo que operaba con Argentina, un país de "adelantos rápidos" y con créditos un "poco largos, de 4 a 6 meses". Dichos rasgos acentuaban, como señalamos previamente, los problemas informativos de los proveedores de créditos y la necesidad de contar con mecanismos informativos más confiables $^{19}$. No obstante, no se han detectado ediciones posteriores de Veritas ni de otros volúmenes similares. Y a pesar de que no es posible determinar la causa de su discontinuidad, podría indicar que este tipo de herramienta informativa no arraigó en la Argentina, a pesar de su amplia difusión en otros países.

En forma complementaria al surgimiento de la prensa especializada, las organizaciones empresarias tales como la Unión Industrial Argentina (industriales) o la Liga de Defensa Comercial (comercio mayorista) organizaron oficinas destinadas a proveer de asesoramiento legal e informes de distinto tipo a sus asociados (patentes, impuestos, legislación, aduanas, etc.). Y específicamente, en la década de 1920, se registró la conformación de dos oficinas cuya función era el intercambio y recolección de información sobre tomadores de crédito, ejerciéndose tales tareas sin fines de lucro. Por tanto, ambas oficinas habrían adquirido características similares en su funcionamiento a los denominados private credit bureau, u oficina de créditos (Japeli y Pagano, 2000).

La Unión Industrial Argentina (UIA), la principal entidad corporativa aglutinante de las empresas industriales, organizó en 1922-1923 una oficina de este tipo. De acuerdo al reporte brindado por la institución, durante el primer año de funcionamiento se recibieron 3.293 pedidos de informes de firmas radicadas en Buenos Aires y en el interior del país. En el período 1923-1924 se despacharon 4.784 informes, cifra que acusaba un incremento de casi el 50 por 100 sobre el primer ejercicio, implicando que cada socio de la UIA, en promedio, había solicitado casi tres pedidos de informes. Para la UIA, estos datos autorizaban a confirmar las previsiones que tuvo el Consejo Directivo al autorizar la organización de esa oficina. Agregaban, además, que "el nuevo servicio social se va desarrollando en forma progresiva a pesar

19 No hemos encontrado registros de libros de referencias posteriores, pero estimamos que deben haberse editado algunos más, aún no localizados. Sólo hemos podido consultar el Latin America Sales Index, editado en el año 1944 por Dun E Bradstreet, Inc. (Baker Library, Harvard Business School). Sobre los criterios clasificatorios puede indicarse que esta misma firma en los años 60 creó el DUNS Number (Data Universal Numbering System), un sistema de numeración codificada de empresas utilizado por numerosas instituciones privadas y públicas en todo el mundo, como un modo de unificar información sobre empresas y grupos económicos, evitándose las confusiones y duplicaciones en las bases de datos e investigaciones. 
de contar con poco personal y menos elementos de labor". E informaban que además de los 4.784 informes enviados a los socios, la oficina había enriquecido su archivo, especialmente con fichas de firmas morosas, calificadas por tanto como "no deseables". Para 1925 la UIA mencionaba haber catalogado unas 50.000 firmas ${ }^{20}$.

En noviembre de 1926, el Boletín mensual de la Cámara de Comercio de Estados Unidos en la República Argentina (AMCHAM) reportaba la creación de la Asociación Mutua de Créditos. La organización de esta entidad fue una propuesta de la casa importadora Will L. Smith ${ }^{21}$. Las empresas que conformaron esta entidad estaban vinculadas en su mayoría al capital norteamericano. La presidencia la ejercía el impulsor de la iniciativa, como representante de la Will L. Smith Inc., y lo acompañaban Mr. A. Heid de la International Harvester Co. El resto de la Comisión Directiva estaba integrada por representantes de las siguientes empresas: Compañía de Cemento Portland, First National Bank Boston, J. I. Case Threshing Machine Co., The National Lead Co. y The House Electric Inter Co. Las firmas que desearan incorporarse debían contar con el apoyo del resto de los miembros, requisito que buscaba facilitar la confidencialidad en el manejo de la información. En el reporte que brindaba la AMCHAM sobre su creación se especificaba que los propósitos de la entidad eran tres: 1) intercambio de información, 2) cobros y asesoramiento en procesos judiciales y 3) realización de reportes especiales. Lamentablemente no ha sido posible detectar información sobre el desenvolvimiento de las dos iniciativas mencionadas, aunque su mera existencia ratificaría la evolución y surgimiento de distintos mecanismos institucionales para aprovisionarse de información.

Los bancos también crearon secciones de informes crediticios. La costumbre del crédito a sola firma en Argentina agigantaba las necesidades de contar con sistemas de informes (Lluch, 2004). Para ello organizaron oficinas destinadas a calcular el crédito que le merecía cada cliente "con señales secretas en sus libros especiales de clasificaciones, responsabilidades y garantías", en forma similar a las que emitían los libros de referencia crediticias (Fernández, 1912). El Banco de la Nación también organizó su sección de informes. Gastón Lestard (1929), gerente de la institución, hacía alusión a "los peligros ocultos en el otorgamiento de créditos sin más que la información recogida sobre cada cliente". En tal caso, un factor común en todas las obras de los analistas de la banca argentina, desde Quesada a Lestard, fue la puntualización de la importancia del sistema de informes (Quesada, 1901; Lestard, 1929). El conocimiento del medio y de los clientes era sindicado como la clave para un ejercicio exitoso de la actividad crediticia.

\footnotetext{
20 Boletín de la Unión Industrial Argentina, Buenos Aires, enero de 1925.

21 "Comments on Argentine Trade", Chamber of Commerce of the United States of America in the Argentine Republic, December 1926, Vol. VI, 5, pp. 25-27.
} 
Mientras que las oficinas organizadas en los bancos no realizaban, salvo excepciones, intercambio de información, hemos visto que los private credit bureau surgieron, al menos desde nuestras evidencias, casi al final del período bajo análisis. Por tanto, y siguiendo lo planteado por Japelli y Pagano (2000), la complejidad y especificidad de la tarea de obtención de referencias explicaría el temprano surgimiento de empresas destinadas a cubrir la demanda de información crediticia.

\section{Las agencias de informes comerciales}

Atendiendo a un fenómeno de dimensiones internacionales, la novedad más importante para afrontar las dificultades de acceso a la información fue el surgimiento de empresas destinadas específicamente, siguiendo la definición brindada por el Diccionario Enciclopédico Larousse de 1900, a "informar, lo más exacto y rápidamente posible, sobre el grado de solvencia de los comerciantes". Años más tarde, una de las firmas locales que estudiaremos se ocupaba de definir al informe comercial como un poderoso auxiliar del movimiento económico:

"puesto que orienta y regula el giro o monto de las operaciones a crédito, al traducir las posibilidades de venta, la solvencia y la honestidad de los presuntos adquirentes, alejando los riesgos de una posible mala operación" 22 .

El origen de estas empresas se remonta al año 1841 en los Estados Unidos. Allí su denominación fue la de commercial credit reporting agencies ${ }^{23}$. El propósito del creador de la primera agencia profesional en dicho país (Luis Tappan's Mercantile Agency, LTMA) fue obtener información objetiva y verificada sobre la responsabilidad de los hombres de negocios visitando el mercado. Vose (1916) relata cómo el creador de la primera agencia, un comerciante minorista de Nueva York, fue víctima de la crisis de 1837 y sus inicios se basaron en los registros de clientes y colegas, naciendo así la firma que más tarde se denominaría G. Dun \& Co. En 1849, John Bradstreet fundó The

22 Rizzuto (1936), p. 41. La definición legal vigente es: “cualquier comunicación escrita, oral o de otro tipo, referida a personas identificadas, que contenga información cuya finalidad sea referirse a su riesgo crediticio". Ruiz (2000), p. 189.

23 Vallieres (2005), en su estudio para Canadá, puntualiza que la expresión en francés para este tipo de empresas es la de agences de renseignements commerciaux, como un equivalente al nombre anglo-norteamericano de commercial credit reporting agency o commercial agency. Otros estudios sobre las credit reporting agencies, su historia y evolución en Olegario (2003) y (2006), capítulo 2; Sylla (2002); y Miller (2003). Una fuente, a la vez que análisis del funcionamiento de Dun E Co., en Vose (1916) y Norris (1978). 
Bradstreet Company, en Cincinnati, convirtiéndose en el mayor competidor de LTMA, y contribuyendo aún más a generalizar el uso de información de crédito, principalmente mediante la publicación de libros con ratings de empresas ${ }^{24}$. En un proceso no exento de dificultades, con críticas a su actuación —en constante evolución organizativa, y de recursos humanos y técnicos para encarar la tarea- y en dura competencia entre ellas, las empresas más grandes del rubro ya se habían consolidado en ese país, a finales del siglo XIX, como una "established business institution". Los estudios disponibles sobre estos procesos remarcan el creciente número y gran espacio de las transacciones en ese mercado como las causas que volvieron paulatinamente menos eficientes los métodos clásicos de guiarse por informes basados en contactos comerciales y en cartas de presentación ${ }^{25}$.

\subsection{Las oficinas de informes comerciales en Argentina}

Las primeras empresas de reportes crediticios fueron creadas por extranjeros, deseosos de transplantar al Río de la Plata una institución que había proliferado desde mediados del siglo XIX en las principales ciudades estadounidenses y europeas. Si bien una rápida mirada y algunas evidencias periodísticas indicarían que la primera empresa de este tipo fue la sucursal abierta por la compañía norteamericana $G$. Dun $\mathcal{E}$ Co., una serie de evidencias documentales nos permiten proponer que la primera agencia específicamente dedicada a la provisión de informes crediticios en Argentina fue Papke \& Dankert, organizada en el año 1892.

La filial de G. Dun \& Co. ${ }^{26}$ - principal empresa del sector a nivel mundial en estos años- fue inaugurada diez años más tarde, en 1902. La oficina de Buenos Aires era la tercera agencia abierta en América Latina y fue parte de un proceso expansivo a nivel mundial. Los registros oficiales muestran cómo la agencia se convirtió en una organización internacional en el período 1891-1916. De un total de 115 nuevas oficinas, 83 de ellas estuvieron localizadas fuera de los Estados Unidos, 77 fueron inauguradas a partir de 1900 y otras 27 durante el trienio de 1901-1903. La apertura de la oficina de Buenos Aires fue una manifestación de la política global de la empresa,

24 En 1933 R. G. Dun se fusionó con The Dun E Bradstreet Co., formando The Dun E Bradstreet, Inc.

25 En otro artículo Madison (1974) analiza los reportes de crédito como fuentes para la historia económica americana, señalando el valor y riqueza (son 2.580 volúmenes) de esta colección documental.

26 En la edición de 1917 de la versión local de Quién es Quién, las referencias a The mercantile agency (Dun E Co) eran: Oficina: Reconquista 37, Casa matriz Nueva York. Gerente: David Young. La casa fundada en Nueva York en 1841 se dedica a suministrar informes comerciales exactos e imparciales acerca de casas o personas en todas partes del mundo. También era editora del Dun's International Review y otras publicaciones periódicas. 
quien anteriormente en Latinoamérica había organizado sucursales en México y Cuba. La agencia de Buenos Aires se ocupaba, además, de atender requisitorias para Paraguay y Uruguay. La estrategia de G. Dun $\mathcal{E}$ Co. fue adelantarse a la demanda y convertirse en recolectores de información para las empresas multinacionales, en especial de origen norteamericano, las cuales lideraron un proceso creciente de expansión en los mercados mundiales durante este período.

Si bien es imposible comparar con la escala que adquirieron en Estados Unidos -incluso por lógica relación con el tamaño de la comunidad de negocios de aquel país-, la Argentina se distinguiría por una significativa expansión de este tipo de empresas, representada en la elevada cantidad de firmas organizadas en distintos momentos. Lamentablemente no se dispone de información para determinar el tamaño o escala de las mismas, y tampoco existen estadísticas uniformes para el período. De todos modos, las distintas referencias halladas permiten identificar tres rasgos.

El primero es la rápida evolución de las empresas de reportes crediticios. Si la primera agencia se organizó en 1892, pronto habrían surgido otras firmas que proveían este servicio. No hemos detectado nombres ni registros, sólo referencias de la propia Papke \& Dankert quien, en la edición de su publicación periódica (Ecos Comerciales y Judiciales) y ante una serie de críticas sobre las agencias en el año 1900, se defendía indicando: "Toda institución que no tenga bases morales muy pronto cae por sí sola, la prueba la tenemos aquí con las muchas oficinas de informes aparecidas y vueltas a desaparecer en los últimos 8 años". En su discurso se arrogaban el derecho de defender, frente a lo que calificaban como ataques injustificados, "una institución que hemos sido los primeros en implantar aquí en el año 1892"27.

El mercado argentino de oficinas de informes crediticios se habría mostrado activo, aunque, como segundo rasgo, presentaba una elevada volatilidad. Las firmas locales aparecían y desaparecían sin dejar casi rastro. La única empresa con continuidad durante las dos primeras décadas del siglo XX fue la filial de G. Dun \& Co. Esta empresa, si bien no hemos podido acceder a sus registros, se habría encontrado más vinculada a la operatoria de firmas extranjeras en la Argentina. Dicha segmentación fue expuesta en un Informe del Departamento de Comercio de los Estados Unidos al recomendarle a los potenciales inversores: "Although the local firms have a very good reputation, the use of American sources of information is recommended" (Hillyer, 1924, p. 22).

La permanencia de la empresa norteamericana puede detectarse fácilmente, pues es la única firma registrada como tal en los censos comerciales de 1904 y 1906 de la ciudad de Buenos Aires. Ello alertaría tanto de la desaparición de las primeras 
agencias o bien de la menor especialización de las empresas locales, que habrían sido registradas bajo otros rubros ${ }^{28}$.

El censo nacional de 1914 no consignó este rubro. En 1922, el Anuario editado por The Standard Directory Company recogió quince agencias de informes comerciales, cuyos nombres eran Acosta y Lara, Agencia Elvas, Brasbie B. M., Contelburgo Ltda., El Cronista Comercial, Dun \& Co., Gasondi D. R., Internacional Credit \& Ration Corp., Multiplex Agency, Pernecco Parodi F. y Cía., R. S. Perrotta y Cía., Pieri A. E. y Cía., Previsión Mercantil, Rizzuto Antonio F. y Young David. Sólo dos años más tarde, el Departamento de Comercio de Estados Unidos, en el citado informe, ratificaba idéntico número. Una empresa extranjera y catorce locales (Hillyer, 1924). Ahora bien, sólo dos años después, cinco casos no coincidían. Ello ilustraría acerca de la inestabilidad —o escasa especialización - del sector, al desaparecer la mitad de las firmas locales. Las empresas presentes en ambos censos, además de Dun $\mathcal{E}$ Co., y por tanto las más estables del sector, habrían sido Brasbie B. M., Contelburgo Ltda., El Cronista Comercial, Internacional Credit \& Ration Corp., Pernecco Parodi F. y Cía., R. S. Perrotta y Cía., Pieri A. E. y Cía., Previsión Mercantil y Rizzuto Antonio F.

El mencionado informe norteamericano de 1924 permite identificar, como tercer rasgo, que la proliferación de agencias de reportes crediticios habría sido una especificidad de la Argentina en términos regionales. En el resto de los países de América Latina no se registraba un número tan elevado de agencias, siendo notable la diferencia entre el contexto argentino y las vecinas economías latinoamericanas, tal como expresa el siguiente cuadro. Como posibles factores explicativos podría encontrarse la conformación temprana de un mercado nacional de productos y créditos (Rocchi, 2006; Regalsky, 1999), aunque mayores exploraciones deben realizarse para poder establecer una afirmación concluyente.

Para el final del período objeto de estudio en este artículo ha sido imposible cuantificar la evolución del número de las agencias de informes crediticios. Pero un cálculo estimativo realizado por la firma Veritas, al considerarse el personal interno y externo empleado en la ciudad de Buenos Aires, propietarios, dirigentes, e informantes, proyectaba la existencia de unas 1.000 personas vinculadas al sector. A este número, la publicación proponía incorporarle los individuos ocupados en el interior del país: agencias, informantes independientes y corresponsales, aumentando así a 10.000 el total de quienes vivían "al amparo de esta manifestación mercantil" (Rizzuto, 1940, p. 138).

28 En el censo general de la ciudad de Buenos Aires de 1904, una sola empresa figuraba bajo el rubro "casas de informes comerciales". Al ser de nacionalidad extranjera consideramos que se trata de G. Dun E Co. Por entonces aparecía registrada con un módico capital de 5.000 dólares y empleando a 23 personas (10 argentinos y 13 extranjeros). 


\section{CUADRO 1}

FUENTES DE INFORMACIÓN CREDITICIA EN VARIOS PAÍSES DE AMÉRICA LATINA, 1924

\begin{tabular}{lccccc}
\hline & Argentina & Uruguay & México & Brasil & Chile \\
\hline Agencias mercantiles extranjeras & 1 & 1 & 2 & 1 & 1 \\
Agencias mercantiles locales & 14 & 0 & 0 & 1 & 0 \\
Bancos estadounidenses & 2 & 2 & 7 & 1 & 1 \\
Bancos locales & 9 & sin datos & 2 & 2 & sin datos \\
\hline
\end{tabular}

$\left({ }^{*}\right)$ Salvo en México, donde también existía una sucursal de Bradstreet Co., la agencia mercantil extranjera es Dun \& Co.

Fuentes: Hillyer (1924), pp. 23-32.

\section{El caso de la empresa Veritas}

Veritas intentaba presentarse como la primera empresa nacional únicamente dedicada a la provisión de informes comerciales. Fue fundada por Antonio Rizzuto ${ }^{29}$, un inmigrante italiano que había trabajado en la firma Pieri y Pernecco Parodi ${ }^{30}$. En los discursos conmemorativos del vigésimo quinto aniversario de la firma, el propio Rizzuto mencionaba explícitamente cómo los quebrantos comerciales posteriores a la crisis de 1914 habían alterado el panorama de tranquilidad. Recordemos que en 1914 se produjo la mayor recesión de la economía argentina. El nivel de pasivos alcanzó los 440 millones de pesos, duplicando los valores del año previo y representando uno de los indicadores más claros del shock externo negativo para la economía abierta del país ${ }^{31}$.

29 Nació en Nocera Tenisere, Calabria, Italia, en 1883. Llegó a Argentina en 1899. Distintas obras conmemorativas lo sindican como empresario, periodista, escritor y sociólogo. En 1946 creó el Instituto Americano de Investigaciones Económicas, Jurídicas y Sociales. En 1949, propuso las bases de la Asociación de la Prensa Técnica Argentina (APTA), de la que fue presidente. En 1960 fundó la Liga Pro Comportamiento Humano. Falleció el 31 de marzo de 1965. Sus tres hijos, desde muy jóvenes, habían estado vinculados a la actividad. Israel (1906) estuvo a cargo de la agencia de reportes crediticios, mientras que Francisco A. (1909) siguió la carrera de periodista y estuvo a cargo de la revista y de las relaciones públicas de la empresa. El tercer hijo, Josué Juan Noé, estaba a cargo de tareas administrativas. Una cuidadosa referencia a la biografía y labor de Antonio Rizutto puede encontrarse en Fundación Rizzuto (1966). Otros datos en el Diccionario Biográfico Ítalo-Argentino. Ambas obras alertan de la polifacética y prolífica actividad del fundador de Veritas. La familia Rizutto controló y gestionó esta empresa durante tres generaciones, antes de que, en 1993, se volviera parte de, y diera su nombre al grupo actual de empresas Veritas S.A., ya en manos de empresas extranjeras. Lamentablemente el archivo de la empresa fue destruido en el momento de su venta.

31 Della Paolera y Taylor (2003), p. 147. En Lluch (2007) se ha analizado las diferentes manifestaciones del fracaso, con énfasis en los quebrantos comerciales, en el mundo empresario argentino hasta 1935. 
La alta cifra de quebrantos mercantiles habría afectado también el desarrollo de los diferentes mecanismos de información crediticia, pues tal como señalaba Rizzuto:

“¿Qué podría interesar la sección de una oficina informativa a los habilitadores del crédito actuantes en ese ambiente de prosperidad sin méritos, es decir en unas horas de prosperidad no soñada? La competencia y la lucha entablada, dificultaba el razonamiento y, por tanto, muy pocos atinaban a confiar la misión informativa y consultiva previa a entidades o personas rectas y escrupulosas... Era el caos. Las estadísticas de quebrantos comerciales mensualmente acusaban cifras enormes. Todo era desconcierto y desorientación"32.

El acceso a una serie de informes y libros editados por la firma Veritas permite avanzar aún más en el estudio de los orígenes de este sector en la Argentina. Según los recuerdos de su fundador, Veritas asumió desde ese día la "grave responsabilidad de aconsejar al comercio habilitador" (Rizzuto, 1936, p. 57). Por supuesto, y como sucedió en otros ámbitos, la agencia debía convencer sobre el valor y seriedad de sus servicios. El objetivo de Rizzuto fue propulsar una estrategia diferencial para, primero, lanzar y, después, mantener a la empresa en el tiempo. Atento al valor de la reputación en este negocio, el fundador de Veritas indicaba que su interés había sido crear "una verdadera institución de informes para el comercio, la industria y la banca, que no fuera una simple oficina de esa índole, sino ante todo un hogar moral para los que a ella pertenecieran y para quienes recurrieran a ella, formada sobre la base de la verdad, la confianza y el honor".

Si la inestabilidad era consustancial al sector, ¿cómo se explicaría entonces la supervivencia de esta empresa? Sobre la base de eficacia en la prestación del servicio y, en especial, en la diferenciación con la competencia más directa, es decir, con las otras agencias de origen argentino. Un aviso publicitario de Veritas resumía los criterios, que a su juicio, le habían permitido permanecer en funcionamiento: "un digno archivo, un servicio rápido, una organización mundial y una eficiente colaboración".

No obstante, el desarrollo de la empresa fue difícil en los comienzos, en los años veinte, si bien logró consolidarse en los treinta. En 1931, la familia Rizzuto fundó la Revista Veritas, pensada como extensión de su labor informática y como "cátedra de doctrina en sus artículos de fondo y un vehículo responsable para la difusión de informaciones económicas, culturales, científicas, tecnológicas y de utilidad general" (Fundación Rizzuto, 1966, p. 32). La revista fue así otro elemento que posicionó a la 
empresa, apuntalando la reputación de la firma en su habilidad para actualizar información y asesorar a la comunidad empresarial.

Un rasgo interesante que vale la pena destacar son los métodos y procedimientos para obtener la información ${ }^{33}$. Rizzuto postulaba que su estrategia fue diseñar un sistema propio para obtener "datos certeros sobre la moralidad y capacidad productora de una firma". En su obra Autorretrato al pastel intentaba explicar su sistema, mencionando que si bien Veritas era una de las tantas agencias informativas de Buenos Aires, había logrado desarrollar un sistema sui generis de información en función de "perpetua actualidad" (Rizzuto, 1943, p. 97).

La primera diferenciación frente a la competencia fue redactar el informe sin apelar a planillas pro-forma completadas por sus informantes. El envío de la planilla, usual en los registros encontrados en la correspondencia recibida por Casa Torro$b a$, por ejemplo, era utilizado como último recurso ${ }^{34}$. Los pedidos de informes podían solicitarse por vía postal, telefónica o telegráfica, contando con empresas abonadas a sus servicios de forma permanente, las cuales recibían un talonario para solicitar los informes comerciales. El servicio se vendía por adelantado y con una validez de 360 días. El precio era uniforme y no impactaba en el costo la extensión o variedad de datos contenidos en el informe.

Una vez que se recibían las solicitudes, se redirigían hacia la oficina de pedidos, cuyo personal se encargaba de localizar el expediente, en caso de que fuera una empresa ya registrada con anterioridad. Quienes estaban a cargo de esta etapa inicial eran dos supervisores. Ambos eran los principales responsables del diseño del informe. Su tarea era analizar y definir cómo se elaboraría el informe, ya que se debía recolectar la información apelando a distintas fuentes: referencias bancarias y comerciales, consulta a informantes y envío de un corresponsal.

Finalizada la investigación y recolección de información, se enviaba a la oficina de revisión. En este sector se controlaba una vez más con la documentación previa, pues se archivaban por orden cronológico los antecedentes, recortes, novedades y también los informes que sobre la misma firma se habían despachado previamente. Desde aquí se enviaba la ficha a la oficina de redacción. Allí, los redactores debían darle forma clara y expresiva, sintetizando las referencias de los antecedentes previos, los envíos de los corresponsales con nuevos datos, las manifestaciones de bienes y los recortes de la prensa.

33 En la actualidad, las fuentes de información de las agencias de reportes crediticios se encuentran reguladas por el artículo 26 de la Ley 25.326, el cual establece que los datos deben ser de fuente pública o facilitada por el interesado o con su consentimiento.

34 Información proveniente de una entrevista semi-estructurada realizada a Jorge Rizzuto, nieto del fundador de Veritas, y quien estuvo vinculado a la actividad hasta la venta de la firma. 
La separación de las oficinas de recepción de pedidos de informes de las de revisión y redacción, respondía al interés de garantizar la confidencialidad. A su vez, los abonados a los servicios informativos de Veritas figuraban con seudónimos anotados en un fichero guardado en la caja de seguridad de la gerencia, a la cual sólo tenían acceso el gerente y el director (padre e hijo, respectivamente) ${ }^{35}$. Una diferencia entre Veritas y la empresa norteamericana Dun $\mathcal{E}$ Co. radicaba, por ejemplo, en que quien realizaba la investigación sobre los antecedentes de la firma no redactaba el informe. Veritas buscaba con ello generar un informe más técnico e impersonal, mientras que en $D$ un $\mathcal{E}$ Co. los pedidos quedaban a cargo de un informante-redactor.

En cuanto a su método de operación, además de los informantes, Veritas contaba con cinco empleados ocupados diariamente en revisar la prensa de la capital y del interior, los diarios, periódicos, revistas mercantiles, industriales y bancarias, y los boletines oficiales y judiciales, para localizar noticias que contribuyeran a completar, aclarar o rectificar la información existente sobre una persona o firma que actuaba en los círculos comerciales del país. Rizzuto en varias de sus obras aludía a la necesaria capacitación de los informantes y al uso de la "ciencia grafológica" o, incluso, la fotografía para determinar sus calificaciones. Tales rasgos provocaban que prefiriera hablar de expedientes en vez de fichas informativas.

Por su parte, el archivo de Veritas para 1934 había crecido considerablemente, contando con 360.000 expedientes de empresas existentes, además del funcionamiento de una oficina jurídica y consultiva (Revista Veritas, 42, Año IV, junio 1934). La estructura organizativa de la empresa se completaba con 18 informantes en la Capital Federal y 3.800 corresponsales en el interior del país, algunos de los cuales no serían otros que los comerciantes reseñados previamente, alertando así de las múltiples formas y estrategias de intercambio de información entre empresas. Complementariamente, en el caso de requerirse información de firmas del exterior, o viceversa, la agencia contaba con convenios con entidades análogas. Dichos acuerdos les permitían a ambas empresas mantener actualizados los registros de firmas con sede en el exterior. A principios de la década de 1940, Veritas mantenía acuerdos con 49 agencias, la mayoría localizadas en los Estados Unidos y Europa ${ }^{36}$.

$35 \quad$ El procedimiento continuaba de esta forma: “El empleado manda el informe a la gerencia para el cliente $x x x$. No sabiendo quien es $x x x$, todas las noches, el gerente y los otros dos hijos del Sr. Rizzuto a todos los cuales ha formado aquel en el respeto de las más absoluta reserva, reciben esos informes, y consultando el fichero, los colocan en sobres, en los que ponen la dirección... el repartidor lleva los sobres, pero ignora que informe es el que contiene cada sobre... de modo que ningún empleado sabe para quién es el informe que prepara ni de quién es el informe que lleva", Revista Veritas, 42, Año IV, junio 1934, p. 11.

36 La ubicación de las empresas que intercambian información con Veritas era Alemania (7), Austria, Bélgica, Bulgaria, China, Cuba, Egipto, España (7), Estados Unidos (8), Finlandia, Francia (5), Holanda, Inglaterra (6), Italia (4), Japón, México, Noruega, Nueva Zelanda, Portugal, Suecia, Suiza y Turquía. 
Por tanto, en un proceso que abarcó las dos primeras décadas de funcionamiento, la empresa fue ganando experiencia, adecuándose a la idiosincrasia local y a los requisitos de sus clientes, y superando las dificultades para aumentar la reputación y credibilidad de sus servicios. Lamentablemente no han quedado registros sobre las actividades de las otras agencias de reportes crediticios para extender estas conclusiones. No obstante, a pesar de la escasez de documentos sobre su funcionamiento, el cruce de la información recolectada permite detectar la existencia de una serie de tensiones que caracterizaron a la primera etapa de funcionamiento de las agencias de reportes crediticios.

\section{Tensiones en los orígenes de las empresas de informes crediticios}

Los debates, el tono defensivo y las ácidas críticas sobre el mercado de agencias locales presentes en los registros periodísticos del ramo, estarían indicando una serie de tensiones y desafíos para el afianzamiento de este tipo de instituciones. En la voz de sus protagonistas, las causas de la problemática trayectoria de las agencias mercantiles se encontrarían en la falta de competencia de algunas de ellas. No es casual que pueda trazarse un claro paralelo entre las notas emitidas desde las páginas de la publicación Ecos Comerciales y Judiciales de la firma Papke E Dankert del año 1900, con las distintas reflexiones — en sus libros o revista- de los Rizzuto (padre e hijo) a finales de los años treinta.

Ambos registros focalizaban su atención, como ya ha sido señalado, en la especificidad del negocio y en la necesidad de diferenciar entre quienes "en vez de llenar escrupulosamente su delicada misión de ser consejeros de buena fe de aquéllos que les han dispensado su confianza, hayan abusado de su posición, haciendo servir su acción como arma difamante" (Ecos Comerciales y Judiciales, 5 de mayo de 1900).

Ante acusaciones periodísticas sobre la funcionalidad y servicios de las agencias de reportes crediticios, titulado como el affaire de las oficinas de informes comerciales, Papke E Dankert en 1900 asumía su defensa, señalando que en otros países las agencias representaban un "valor útil, necesario y apreciado", y, por tanto, no debía plantearse su desaparición en términos generales. La solución, consideraban, era recurrir a la justicia y aislar a quienes desempeñaban inescrupulosamente la tarea de suministrar referencias. También aclaraban, tal como harían los Rizzuto treinta años después, que como ninguna agencia podía prometer un servicio infalible, el comerciante antes de solicitar un reporte "debía conocer a las agencias, su grado de responsabilidad y su modo de trabajar".

Para poder desentrañar estos niveles de tensión es importante regresar a las características del reporte comercial. Es útil en tal sentido la definición provista por uno de los empresarios del sector: 
"El informe, intrínsecamente, constituye un documento moral de carácter probatorio del grado de responsabilidad que efectivamente ofrece la persona o entidad informada. Por ese sólo hecho se constituye en un arma delicada y temible, que, según sea la mano que la maneje, puede ser de salvación o de condena" ${ }^{37}$.

Y como arma, podía utilizarse de diversas maneras, hasta alcanzar —en dos definiciones esbozadas por Francisco Rizzuto - la forma de un "informe ganzúa" o de "atraco informativo". En este punto vale la pena aclarar que estas tensiones no enunciarían una excepcionalidad del caso argentino, aunque en cada contexto fue diferente la adaptación de estas instituciones empresariales ${ }^{38}$. Indicios recolectados en obras de opinión sobre el mundo de los negocios son claros en relación a las dificultades para transplantar esta institución foránea al medio local. Por ejemplo, William Lough, en 1915, consideraba como moderado el proceso de inserción de estas empresas: "For these reasons, the inadequacy of the old-time system, of estimating credit through purely personal relations and impressions has shown itself in its true light and has been to a considerable extent reformed. An American mercantile agency in Buenos Aires is doing its part toward popularizing the practice of giving financial statements" (Lough, 1915, p. 22).

En forma aún más clara se expresaba Santamarina en su obra dedicada a la presentación de Argentina para la mirada extranjera en 1912 al señalar "The pioneer work of establishing branches of a mercantile agency in Spanish American countries proved to be a very hard proposition. Merchants and others could not understand how disclosing their affairs to a foreign concern could benefit them, and they looked upon it as a piece of impertinence and trespass into their privacy. The trained men sent by R. G. Dun E Co. to those countries for that purpose had to withstand many and continued rebuffs for a long time and to exercise great patience and diplomacy to overcome prejudice" (Santamarina, 1912, p. 158).

Y si bien la pionera en vencer prejuicios y superar dificultades no fue la empresa G. Dun $\mathcal{E}$ Co., es evidente que el oficio se prestaba para falsificaciones y abusos. En una postura claramente defensiva, Papke $\mathcal{E}$ Dankert señalaba en 1900 que las deficiencias de los informes locales no sólo se debían a problemas éticos de algunos colegas, sino también a un ambiente de negocios donde "los contratos sociales sólo existen en estado de proyecto y basados en convenios verbales, cuando no deficientes, por acusar capitales ilusorios, donde la matrícula comercial es letra muerta y la con-

37 Revista Veritas, 42, Año IV, junio 1934.

38 En el caso norteamericano, la consolidación de estas empresas tampoco fue sencilla. Tuvieron que superar varias dificultades, desde ganar la confianza de la comunidad comercial y financiera, hasta mejorar su organización, lo que incluyó transitar hacia el modelo de agentes full-time, mejorar los métodos de control de sus empleados, recolectar la información de varias fuentes y afrontar las demandas legales que arreciaron, en la década de 1870, al recibir denuncias por espionaje e invasión de privacidad. Véase Norris (1978). 
tabilidad reducida a su más simple expresión" (Ecos Comerciales y Judiciales, Año VII, 346, 12 de mayo de 1900). Por lo delicado de la tarea y las particularidades del medio empresarial local, los discursos de los agentes se encontraron fundamentalmente volcados a resaltar la necesaria idoneidad para ocuparse del negocio.

Un segundo y complementario nivel de problemas se vinculaba con las dificultades técnicas del oficio (buenos archivos y noticias renovadas), junto con la necesidad de yuxtaponer fuentes. En los años críticos de la década de los treinta se centró en este nivel el foco del debate periodístico. Es evidente que las agencias de reportes crediticios sólo podían tener éxito, reduciendo las asimetrías de información, si los datos brindados eran fiables. A pesar de ello, las referencias durante estos años acerca de la idoneidad y la dudosa calidad de la información suministrada en los reportes comerciales fueron un rasgo dominante, acompañado por el fuerte discurso defensivo de algunas de las agencias establecidas ${ }^{39}$.

Ligado a lo anterior, y como un tercer rasgo problemático, se encuentran los propios criterios utilizados para clasificar a los tomadores de crédito. Las críticas por tratarse, al principio, de un sistema inquisitivo y, años más tarde, por las consecuencias de los posibles errores al momento de clasificar la clientela, alertan acerca de las dificultades para imponer un sistema profesional de referencias crediticias. Este tercer nivel es clave pues aún no existía un sistema formal de clasificación. Los criterios valorativos, como sucedía en otros contextos contemporáneos, ocupaban un lugar central en los informes ${ }^{40}$. Durante estos años el carácter fue un sustituto frente a la ausencia o falta de estandardización de criterios para evaluar a los tomadores de crédito. En la primera publicación dedicada específicamente al tema, el Veritas (1889), los informes eran de naturaleza mixta. El abanico para la clasificación como sujeto de crédito era amplio. Los ratings de letras funcionaban a modo de categorías que sintetizaban información cuantitativa y cualitativa. La máxima categoría era A1 (con crédito ilimitado), pasando por otras once graduaciones menores (de 200.000 a 3.000) para descender hasta aquéllos para los cuales se les reservaba otras 8 categorías hasta la abstención: $\mathrm{V}$, véase el modo de trabajar; $\mathrm{D}$, moralidad dudosa (aún se dice); $\mathrm{Z}$, pedirnos informes complementarios; $N$, poco capital, crédito 400; $X$, crédito discutido s/la plaza; 4, quisquilloso (aún se dice); $B$, ha hecho malos negocios (aún se dice); y U, abstenerse.

39 Un ejemplo más contemporáneo de este rasgo son los avatares para la sanción de la Ley Nacional 25.326, de Protección de datos Personales, tras cinco años de discusiones. Esta ley fue aprobada en noviembre de 2000. La misma tardó un año más en reglamentarse. Desde el momento de su sanción se han presentado veintitrés proyectos de modificaciones.

40 En la normativa jurídica actual claramente se expresa que los juicios valorativos no son admisibles en los informes comerciales, dado que introducen la posibilidad del error al momento de juzgar y condicionan al receptor. Véase, al respecto, el análisis que realiza Ruiz (2000). 
No sólo se adscribía a cada firma un tope máximo crediticio (rasgo asociado a los informes modernos), sino que se le adosaba una calificación sobre sus "cualidades", basadas en concepciones "espirituales" de las firmas. Las categorías en esta faceta pueden ilustrarse con términos como serias, honradas, muy honorables, trabajadoras, de primer orden, entre otras. En tal sentido, y si bien este sistema carecía de la sofisticación de los sistemas modernos de análisis de riesgo crediticio, las prácticas del siglo XIX y temprano XX en la Argentina, así como en otros contextos, combinaban elementos objetivos y subjetivos.

Reputación, moralidad y concepto general eran evaluados, en donde el grado de cumplimiento (bueno/regular) y la trayectoria se yerguen como los ejes centrales desde los cuales se clasificaba a los comerciantes ${ }^{41}$. Aspectos que resumía José Mieres en su libro sobre la moral comercial al señalar: "El crédito es el producto de la historia general de un comerciante multiplicado por la responsabilidad del mismo. Prueba de la fuerza de la moral aún en lo más rudo del mercantilismo es que, el hombre sin capital pero con buena historia, consigue crédito, y, el hombre con él, pero de mala fe no lo consigue" (Mieres, 1918, p. 204).

Límites éticos y abusos, información no verídica o falsa y criterios subjetivos en la elaboración de los reportes habrían de constituir los ejes sobre los cuales se centraban las tensiones alrededor del oficio informativo. Estos tres rasgos llevaron la discusión a un cuarto nivel: los debates alrededor de la regulación del sector.

Las obras de los Rizzuto (padre e hijo) permiten observar que sus reclamos y ansiedades, si bien remitían a la órbita privada (apelaciones a la moral del informante), también solicitaban la imperiosa necesidad de una regulación legal con el propósito de "evitar la industria del informe 'chantage'" (Rizzuto, 1936; Rizzuto, 1940, p. 36). Dicha preocupación también escondía su interés en defender la profesión de "informador", pues las querellas (reales o posibles) por calumnias e injurias acompañaron al sector desde sus orígenes.

Una duda rondaba en el ambiente durante estos años: ¿constituía el informe comercial un delito de injuria o de difamación contra el honor de las personas? Los Rizzuto (1936 y 1940) se defendían señalando que el oficio se basaba en el derecho a informar, y, por ello, no se podía admitir "animus injuriando". Su actividad y función era procurar referencias informativas basándose en el "animus consulendi". La posibilidad de errores o malos usos, provocaba que ambos reconocieran la necesidad de un código o ley que reglamentara el ejercicio de las agencias informativas. 
Ningún tipo de regulación específica del sector se produjo en estas décadas ${ }^{42}$. La discusión se mantuvo al margen de todo análisis legislativo si bien, claro está, la actividad se hallaba regida por el Código de Comercio. La provisión de informes crediticios, en tanto, estuvo sujeta a la aplicación, en forma supletoria, de lo establecido en los Códigos Civil y Penal respecto de delitos tales como injuria y difamación, daño moral y vulneración de los derechos de libertad de imprenta, entre otros ${ }^{43}$.

Lentamente, a partir de la década de 1940, comenzaron a registrarse cambios, como las primeras regulaciones y el surgimiento de organizaciones como la Cámara de Dirigentes de Información y Crédito (CADIC), destinada a generar alianzas de colaboración interempresariales en un sector que, históricamente, se caracterizó por las tensiones y los debates a su alrededor. Asimismo, la reglamentación de los informes — pero no así de la actividad — se promovió sólo recientemente (2001) y fue producto de un contexto donde se han alterado las bases de operación de estas empre$\operatorname{sas}^{44}$.

\section{Conclusiones}

La expansión del sector comercial en la Argentina de principios del siglo XX y las estrategias desarrolladas por las empresas habilitadoras para obtener información, fueron dos rasgos centrales que esperamos haber reseñado en estas páginas. En este último nivel nos interesó poner de manifiesto cómo los propios comerciantes generaron mecanismos endógenos de información. Asimismo, postulamos que los mecanismos directos e indirectos se complementaron, generándose distintas respuestas

42 Como se indicó, en la Argentina son de aplicación a las agencias de informes comerciales la Ley 25.326, (Ley de Protección de Datos Personales), el Decreto Reglamentario 1558/01 y las Directivas que establezca la Dirección Nacional de Protección de Datos Personales, un ente autónomo, integrante del Ministerio de Justicia y encargado de regular lo referente al tratamiento de los datos personales.

43 De acuerdo al análisis de Ruiz (2000), pp. 71, 101 y 196, la jurisprudencia argentina y la doctrina especializada han establecido en los últimos años que no se viola la intimidad al dar a conocer a terceros datos económicos referidos a la producción de determinados hechos trascendentes al comercio.

44 La Ley 25.326 está destinada a regular la protección integral de los datos personales asentados en archivos, registros, bancos de datos u otros medios técnicos de tratamiento de datos, sean éstos públicos o privados, destinados a dar informes, para garantizar el derecho al honor y a la intimidad de las personas y permitir el acceso a la información que sobre las mismas se registre. Como explica Ruiz (2000), frente al avance de la actividad informativa han surgido especiales tutelas para los derechos de los ciudadanos. El habeas data, de acuerdo a este autor, cumple un doble rol: como medio regulatorio de una actividad informativa que hasta hoy no está reglamentada; y como medio de protección de los datos personales (Palazzi, 1997). Para la regulación de los reportes crediticios empleados en el crédito al consumo, y por tanto personal, en Estados Unidos, véase Hunt (2002). 
institucionales al problema de la asimetría de la información en el expansivo mercado de crédito comercial del período.

El acceso a documentación inédita de una empresa dedicada a la comercialización de productos en el interior de la Argentina, y en especial a las copias de los reportes crediticios enviados a sus distintos proveedores y bancos radicados en Buenos Aires, permitió reconstruir la dinámica de tales requerimientos en el transcurso de las tres primeras décadas del siglo XX. La pervivencia de canales informales se habría debido tanto a fortalezas propias de este mecanismo (confianza en sus informantes y gratuidad), como a las debilidades en la consolidación de un sector profesional de agencias, y a lo limitado y tardío de la aparición de otros mecanismos, como los private credit bureau. En tal sentido, los canales informales basados en la colaboración interempresarial cubrieron una cuota en el intento de reducir la información asimétrica en los mercados crediticios. No obstante, la magnitud creciente de las operaciones, en escala y complejidad, así como las tensiones alrededor de los denominados desastres comerciales, habrían limitado la práctica de utilizar sólo las vías informales.

Argentina aparece como un caso de surgimiento temprano de empresas especializadas en proveer informes crediticios. Los orígenes del sector se encontraron ligados tanto a inmigrantes deseosos de implantar en el Río de La Plata esta institución comercial, como al funcionamiento de la empresa norteamericana Dun \& Co., líder en el sector a nivel mundial, que buscaba responder a la demanda de un mercado en expansión. Por tanto, Argentina se caracterizaría por el rápido y temprano surgimiento de un sector profesional de agencias de reportes crediticios, que al generar información y distribuirla contribuyó al desarrollo de los mercados crediticios y financieros durante el período.

Este sector se habría caracterizado entonces por un alto dinamismo pero, a la par, por una elevada inestabilidad. La falta de información cuantitativa para este período, así como la escasez de información de las propias empresas, limitó la profundización de nuestra mirada sobre la dinámica expansiva del sector. No obstante, las evidencias recogidas permitieron postular la desaparición de la mayoría de las empresas argentinas organizadas a inicios del siglo XX, con excepción del caso Veritas, que sobrevivió en manos de la familia Rizzuto hasta 1993.

También indicamos que los debates, el tono defensivo y las ácidas críticas sobre el mercado de agencias locales presentes en los registros periodísticos del ramo, estarían indicando una serie de desafíos para el afianzamiento de este tipo de instituciones: límites éticos y posibles abusos, uso de información no verídica o falsa, o falta de criterios estandarizados para la calificación crediticia. Y si bien no serían rasgos propios de la experiencia argentina, en estos niveles se reflejan los diferentes aspectos que dificultaron la consolidación del sector, destacándose también la falta de regulación legal de la actividad. Cada uno de estos niveles adquirió, además, espe- 
cificidades propias e implicó un proceso de adaptación de una institución foránea al medio local.

Las diferentes evidencias recogidas mostraron que la liberalidad en el otorgamiento del crédito comercial, y en especial los largos plazos de las ventas, generaron un alto nivel de endeudamiento comercial y un ambiente propicio para el temprano surgimiento de especialistas en vender información crediticia. Por último, esperamos haber puesto de manifiesto las distintas transformaciones y adaptaciones de este tipo de empresas al ser trasplantadas a la Argentina, siendo el más fiel exponente de tal proceso los métodos sui generis de la firma Veritas para generar sus informes crediticios. Esta empresa surgió tras el pico de quebrantos de 1914 y diseñó un sistema propio de referencias, consolidándose en los años treinta y logrando perdurar hasta inicios de los noventa en manos de la familia fundadora. Las agencias que sobrevivieron debieron cuidar su reputación para ganar la confianza de sus clientes y estar atentas a un cambiante y dinámico contexto económico-social durante las primeras décadas de su existencia.

\section{Bibliografía}

AYALA ESPINO, José (1999): Instituciones y economía. Una introducción al neoinstitucionalismo económico, México, Fondo de Cultura Económica.

BROWN, Jonathan (2002 [1979]): Historia Socioeconómica de la Argentina, 1776-1860, Buenos Aires, Instituto di Tella y Siglo XXI de Argentina Editores.

BROWN, Jonathan, y ROSE, Mary (1993): Entrepreneurship, network and modern business, London, Manchester University Press.

CASSON, Mark (1997): Information and organization. A new perspective on the theory of the firm, Oxford, Clarendon Press.

CASSON, Mark, y ROSE, Mary (1998): Institutions and the evolution of modern business, London, Frank Cass.

CORTÉS CONDE, Roberto (1982): “Aspectos económicos en la formación de las ciudades argentinas", en AA. VV., De historia e historiadores. Homenaje a José Luis Romero, México, Siglo XXI.

DELLA PAOLERA, Gustavo, y TAYLOR Alan (2003): Tensando el ancla: La Caja de Conversión argentina y la búsqueda de estabilidad macroeconómica, 1880-1935, Buenos Aires, Fondo de Cultura Económica.

DIAZ ALEJANDRO, Carlos (1983): Ensayos sobre la historia económica argentina, Buenos Aires, Amorrortu.

DIRECCIÓN GENERAL DE COMERCIO E INDUSTRIA (1914): Censo Comercial e Industrial de la República, Buenos Aires, Talleres Gráficos del Ministerio de Agricultura. 
Ecos Comerciales y Judiciales (1900), Buenos Aires, Papke \& Dankert.

FERNÁNDEZ, Alejandro (2004): Un "mercado étnico" en el Plata. Emigración y exportaciones españolas a la Argentina, 1880-1935, Madrid, Consejo Superior de Investigaciones Científicas.

FERNÁNDEZ, Juan (1912): La Banca Argentina, El carácter del Banco Español y su modo de funcionar, Buenos Aires.

FUNDACIÓN RIZZUTO (1966): Vida, obra y pensamiento de Antonio Rizzuto, Buenos Aires, Fundación Rizzuto.

HILLYER, Arthur S. (1924): "Sources of foreign credit information", Trade Informational Bulletin, 292, Washington DC, Department of Commerce, Bureau of Foreign and Domestic Commerce.

HOFF, Karl, y STIGLITZ, Joseph (1990): “Imperfect information and rural credit markets: puzzles and policy perspectives", World Bank Economic Review, 4, pp 235250.

HOMBRES DEL DÍA (1917): El diccionario biográfico argentino en el cual se ha incorporado "Who's who in Argentina", Buenos Aires, Sociedad Inteligencia Sudamericana.

HUNT, Robert (2002): "The development and regulation of consumer credit reporting in America", Research Department, Working Paper, 02-21, Philadelphia, Federal Reserve Bank of Philadelphia.

JAFFEE, Dwight M.; y THOMAS, Russell (1976): “Imperfect Information, Uncertainty, and Credit Rationing", Quarterly Journal of Economics, 90, November, pp. 651-666.

JAPPELLI, Tullio, y MARCO, Pagano (2000): “Information Sharing in Credit Markets: a Survey", CSEF Working Paper, 36, Salerno, University of Salerno.

LELAND, Hayne, y PYLE, David (1977): "Informational asymmetries, financial structure and financial intermediation", The Journal of Finance, 32, 2, pp. 412-415.

LESTARD, Gastón (1929): El Crédito Bancario. Tecnicismo y práctica del descuento y normas científicas y económicas para la distribución de los préstamos, Buenos Aires, A. García Santos.

LLUCH, Andrea (2004): “Comercio y Crédito en La Pampa a inicios del siglo XX. Un estudio sobre el papel económico de los almacenes de ramos generales", Tesis Doctoral inédita, Universidad Nacional del Centro de la Provincia de Buenos Aires, Tandil.

-(2006): “Comercio y crédito agrario. Un estudio de las prácticas y lógicas crediticias de los comerciantes de campaña a comienzos del siglo XX", Boletín del Instituto de Historia Argentina y Americana Dr. Emilio Ravignani, 29, Buenos Aires, pp. 51-83.

-(2007): "Fisonomía de los 'fracasos' empresarios en la Argentina de principios de siglo XX: reflexiones preliminares", ponencia presentada al Primer Congreso Latinoamericano de Historia Económica, Montevideo, Uruguay. 
LOUGH, William (1915): "Banking opportunities in South America”, Special Agents Series, 106, Washington DC, Department of Commerce, Bureau of Foreign and Domestic Commerce.

MADISON, James (1974): “The evolution of commercial credit reporting agencies in 19 century America", Business Economic Review, 48, 2, pp. 164-186.

MIERES, José (1918): La moral comercial, Buenos Aires.

MILLER, Margaret (2003): “Credit Reporting Systems Around the Globe: The State of the Art in Public and Private Credit Registries", en MILLER, Margaret (ed.), Credit Reporting Systems and the International Economy, Cambridge, MIT Press, pp. 25-80.

NORRIS, James (1978): D. R. G. Dun E Co., 1841-1900: The development of credit-reporting in the nineteenth century, Westport, Conn., Greenwood Press.

OLEGARIO, Rowena (2003): "Credit-Reporting Agencies: A Historical Perspective", en MILLER, Margaret (ed.), Credit Reporting Systems and the International Economy, Cambridge, MIT Press, pp. 115-160.

-(2006): A culture of Credit: embedding trust and transparency in American Business, Cambridge, Harvard University Press.

PAGANO, Marco, y JAPPELLI, Tullio (1993): "Information Sharing in Credit Markets", Journal of Finance, American Finance Association, 48, 5, pp. 1693-1718.

PALAZZI, Pablo (1997): "El habeas data y el derecho al olvido", Jurisprudencia Argentina, I, 33, pp. 33-42.

POWELL, Walter (1990): “Neither Market nor Hierarchy: Networks Forms of Organization", Research in Organizational Behavior, 12, pp. 295-336.

QUESADA, Sixto (1901): Historia de los bancos modernos, Buenos Aires, Biedma e Hijo editores.

REGALSKY, Andrés (1999): “Banca y capitalismo en la Argentina, 1850-1930. Un ensayo crítico", Revista Ciclos, IX, vol. IX, 18, pp. 33-54.

Revista Veritas (1931-1939), Buenos Aires, Institución Veritas.

RIZZUTO, Antonio (1936): Perfiles del informe comercial, Buenos Aires, Porter Hnos.

-(1943): Autorretrato al pastel, yo y mi obra, Buenos Aires, Guillermo Kraft Ltda.

RIZZUTO, Francisco A. (1940): Radiografía del informe comercial, Buenos Aires.

ROCCHI, Fernando (2006): Chimneys in the Desert: Industrialization in Argentina during the Export Boom Years, 1870-1930, Stanford, Stanford University Press.

RUIZ MARTÍNEZ, Esteban (2000): Los informes comerciales y el derecho a la información, Buenos Aires, Editorial Ábaco de Rodolfo Depalma.

SANTAMARINA, Juan Pedro (1912): The argentine Republic, Development, facts and trade features, New York.

STIGLER, George (1961): "The economics of information", The Journal of Political Economy, LXIX, 3, pp. 213-225.

STIGLITZ, Joseph, y WEISS Andrew (1981): "Credit Rationing in Markets with Imperfect Information", The American Economic Review, 71, 3, pp. 393-410. 
SYLLA, Richard (2002): "An historical primer on the business of credit ratings", en LEVICH, Richard M.; MAJNONI, Giovanni, y REINHART, Carmen (eds.), Ratings, rating agencies and the global financial system, New York, Kluwer Academic Publishers, pp. 19-40.

VALLIERES, Marc (2005): Crédit, commerce et bourgeoisie d'affaires au XIXe siècle: le système des agences de renseignements commerciaux, Laval, Université Laval, Rapport de recherche, Département d'Histoire.

VERITAS (1889): Financiero, comercial e industrial de la América del Sur, París, Marcel Picard.

VOSE, Edward Neville (1916): Seventy-five years of the Mercantile agency, R. G. Dun \& Co., 1841-1916, Brooklyn, N. Y. R. G. Dun \& Co. 